\title{
РАЗВИТИЕ ИНСТИТУЦИОНАЛЬНОЙ СРЕДЫ КАК УСЛОВИЕ ТРАНСФОРМАЦИИ ФОРМ СОБСТВЕННОСТИ
}

\author{
(c) 2021 Карамова Ольга Владимировна \\ доктор экономических наук, профессор \\ Финансовый университет при Правительстве Российской Федерации \\ E-mail: okaramova@fa.ru \\ ORCID: 0000-0003-3713-7994
}

Статья посвящена проблеме развития институциональной среды, под воздействием таких факторов, как инновационные- и интернет-технологии, сетевые структуры, цифровизация экономики и общества. Институциональная среда создает предпосылки для трансформации форм собственности и появления новых организационно-правовых отношений в экономике. В статье рассмотрены направления модификации форм собственности по субъекту, по объекту и способу закрепления за каждым правомочием определенного субъекта собственности.

Ключевые слова: формы собственности, институциональная среда, «информационная эпоха по М. Кастельсу», цифровая экономика, интернет-бизнес, сетевая структура.

В теории собственности сконцентрированы самые важные и практически значимые экономические интересы отдельных людей, фирм и общества. Этим объясняется ведущее место экономической категории собственности в научных исследованиях на всех этапах развития экономической науки. Проблема собственности является очень острой, но в экономической науке так и не выработана единая трактовка этого понятия.

Широкое распространение институциональной теории собственности связано с тем, что она объясняет реальные существующие условия деятельности экономических субъектов в условиях рыночной экономики.

Экономическое содержание процесса модификации форм собственности непосредственно связано с сущностью собственности как экономического отношения в воспроизводственном процессе.

Модификация форм собственности возможна по ряду направлений, связанных с изменением, трансформацией и созданием совершенно новых экономических отношений:

1. Существенным направлением модификация форм собственности является трансформация субъекта собственности. Поскольку субъектом может быть не просто индивид, группа индивидов или организация. Субъект собственности может быть представлен сочетанием этих акторов в самом неожиданном или причудливом виде. Например, сетевые платформы, в ко- торых собственниками разных видов объектов могут выступать частные лица, фирмы, государство, партнерства. Примером модификации форм собственности являются финансовые рынки, корпорации, «народный капитализм» и др.

2. Важным направлением модификации форм собственности становится объект собственности. В XX веке такая модификация была связана с появлением собственности не только в виде физических объектов, но и в форме интеллектуальной собственности. Развитие рыночных отношений и расширение влияния финансовых рынков привела к необходимости оценки собственности., от методик проведения которой зависит величина актива, находящегося в собственности. В XXI веке модификация форм собственности по объекту происходила по направлению все большего расщепления прав собственности на отдельные элементы общего объекта. Например, в науке при выпуске технологически новой продукции, в информационнокоммуникационной сфере экономики, в искусстве и культуре, в индустрии спорта и др.

3. Следующим видом модификации форм собственности является изменение способа закрепления за каждым правомочием определенного субъекта собственности. Развитие форм собственности в этом направлении связана с расщеплением прав собственности на отдельные пучки и проблемой спецификации прав собственности в разных формах. Например, передача прав собственности через лизинг, широ- 
кое развитие франчайзинга, аутсорсинга, паевых форм собственности.

Институциональная теория прав собственности изучает одну из важнейших сфер институциональной среды динамично развивающуюся под воздействием цифровых технологий.

Роль государства в развитии форм собственности заключается в развитии институциональной среды. В российской практике таким примером может служить программа и фонд под названием «Национальная технологическая инициатива» (НТИ).

Смысл этой долгосрочной комплексной программы заключается в том, что она направлена на создание условий по обеспечению лидерства российских компаний на рынках, связанных с новыми высокими технологиями и будущей конкурентной структурой мировой экономики на предстоящие 10-25 лет.

На государственном уровне Национальная технологическая инициатива определена как приоритет в государственной политике. «На основе долгосрочного прогнозирования необходимо понять, с какими задачами столкнётся Россия через 10-15 лет, какие передовые решения потребуются для того, чтобы обеспечить национальную безопасность, высокое качество жизни людей, развитие отраслей нового технологического уклада».

«Национальная технологическая инициатива» предполагает объединение усилий в рамках широкой коалиции, которая основана на формировании проектных групп, включающих представителей разных сфер:

- технологические предприниматели, крупные деловые объединения России;

- ведущие университеты и исследовательские центры, экспертные и профессиональные сообщества;

- институты развития и заинтересованные органы исполнительной власти.

Институциональная инфраструктура обеспечивается, помимо прочего, различными государственными программами по развитию цифрового общества» [4]. Попов Е. В. предлагает типологизацию принципов цифровизации хозяйственной деятельности, выделяя принципы децентрализации ресурсов и эволюционного развития.

В настоящее время развитию цифровой экономики в Российской Федерации препятствует наличие следующих проблем:

- не зрелость институционально-правовых механизмов защиты прав лиц, создающих и применяющих цифровые технологии в гражданскоправовых отношениях;

- отсутствие признания цифровых объектов в качестве нового типа доказательств;

- не разработанность должной компетенции у судебных и административных органов для рассмотрения споров, возникающих в условиях цифровой экономики.

Таким образом, модификация форм собственности происходит под воздействием большого количества факторов, поскольку отношения собственности являются стержнем экономической системы.

Систематизация факторов, трансформирующих формы собственности, может быть осуществлена на основе разных критериев: концептуального подхода, содержательного принципа, эволюционно-исторического, системного и процессного подходов. Экономические факторы, такие как конкуренция и кооперация, влияют на модификацию крупного бизнеса в мировой и российской экономике. Модификация ТНК заключается в создании глобальных цепочек добавленной стоимости, в рамках которых происходит комбинирование разных форм собственности по национальной принадлежности и по форме собственности.

Снижение экономических и трансакционных издержек модифицирует формы собственности в виде аутсорсинга, франчайзинга, интернетбизнеса. Важным направлением является появление таких организационно-правовых форм бизнеса, которые способны осуществлять кастомизацию продуктов и услуг.

Сетевая структура, модифицирующая формы собственности, рассматривается как самостоятельный механизм экономического взаимодействия на ряду с рыночный механизмом и взаимодействием в иерархии. Сетевые структуры функционируют на основе информационнокоммуникативных технологий, становятся наиболее релевантной организационной моделью предпринимательства для сложных и динамичных, постоянно изменяющихся структур при сохранении гибкости организаций и институтов.

В условиях цифровой экономики происходит развитие всех институтов и в первую очередь института собственности. Для современной 
эволюции института собственности характерно усиление определенных эффектов:

«1. Сложностью механизмов контроля.

2. Деперсонификацией собственников (формированием нетранспарентной структуры собственности).

3. Поведенческими искажениями при восприятии стимулов частной собственности.

4. Усилением государственного регулирования и рационирования.

5. Доминированием института властисобственности» [2].

М.Кастельс уделяет внимание новому типу предприятия в виде сетевых структур и информационных платформ с позиций опыта в разных национальных институциональных средах, активно используя подход кейсов.

Можно согласиться с Поповым Е. В. в том, что «отличительная особенность цифровизации хозяйственной деятельности заключается в развитии институционального обеспечения бизнеса.
Формирование устойчивой институциональной инфраструктуры гарантирует снижение трансакционных издержек фирм при взаимодействиях посредством цифровых технологий.

Среди наиболее важных цифровых технологий для предпринимательства следует выделить такие, как технологии сбора, обработки и анализа больших данных; облачные технологии в виртуальной и дополненной реальности; машинное обучение, проекты и технологии блокчейна, Интернет-вещей, цифровые платформы, искусственный интеллект, 3D печать.

Российская интернет-экономика характеризуется ростом, за период с 2011-2020 гг. по аналитическим исследованиям объем интернет-торговли рос в среднем за год на 25$28 \%$ и увеличился с 235 млрд. до 1,72 трлн. рублей [5].

Права собственности в условиях интернетпредпринимательства могут расщепляться и передаваться в разных комбинациях. Важной

Таблица 1. Принципы онтологии и экономического анализа «информационной эпохи» и цифровизации хозяйственной деятельности по М. Кастельсу [3].

\begin{tabular}{|c|c|}
\hline Принцип & Сущность принципа \\
\hline \multicolumn{2}{|c|}{ Принципы онтологии } \\
\hline Анализ субъекта хозяйственной деятельности & $\begin{array}{l}\text { Базовой единицей хозяйствования экономической органи- } \\
\text { зации становится не индивидуальный субъект или кол- } \\
\text { лективная организация (корпорация, государство), а сеть. } \\
\text { Единицей становится сеть, состоящая из разнообразного } \\
\text { множества субъектов }\end{array}$ \\
\hline $\begin{array}{l}\text { Этический принцип как фундамент сетевого } \\
\text { предприятия }\end{array}$ & $\begin{array}{l}\text { Это не единая «сетевая культура» в смысле систем ценно- } \\
\text { стей, а «общий культурный код», многоликая виртуальная } \\
\text { культура, созданная многочисленными участниками в } \\
\text { разном институциональном окружении при выработке } \\
\text { стратегий. «Культурный код» действенная сила, так как дает } \\
\text { информацию для властных экономических решений в каж- } \\
\text { дый момент жизни сети. }\end{array}$ \\
\hline Изменчивый геном сетевого предприятия & $\begin{array}{l}\text { Краткосрочность существования «культурного кода» сете- } \\
\text { вого предприятия, изменение под воздействием многих } \\
\text { факторов виртуальной реальности. Попытка кристаллиза- } \\
\text { ции позиций в сети, как культурного кода, приговаривает } \\
\text { сеть к устранению }\end{array}$ \\
\hline \multicolumn{2}{|c|}{ Принципы экономического анализа } \\
\hline «Дух информационализма» & $\begin{array}{l}\text { Сочетает принцип «созидательного разрушения» Йозефа } \\
\text { Шумпетера, ускоренного до скорости оптических элек- } \\
\text { тронных цепей, и принцип культурно-институциональных } \\
\text { трансформаций Макса Вебера. }\end{array}$ \\
\hline Исторический подход & $\begin{array}{l}\text { Рассматриваются корни капитализма и трансформация } \\
\text { хозяйственной деятельности в последние два века в резуль- } \\
\text { тате становления информационного общества. }\end{array}$ \\
\hline Кейсовый метод & $\begin{array}{l}\text { Изучение хозяйственной практики на примере большого } \\
\text { количества фирма разного типа: малых и средних предпри- } \\
\text { ятий, корпораций, стратегических альянсов, сетей. }\end{array}$ \\
\hline $\begin{array}{l}\text { Институционально-культурологический } \\
\text { подход }\end{array}$ & $\begin{array}{l}\text { Рассмотрение институционального окружения многих } \\
\text { стран в Северной Америке, Западной Европе, Японии, Ки- } \\
\text { тае, России, Латинской Америке }\end{array}$ \\
\hline
\end{tabular}


проблемой для реализации интернет-бизнеса является размывание и спецификация прав собственности.

Для отечественной электронной коммерции характерно наличие большого количества средних и мелких интернет-магазинов. Их малые обороты не позволяют им создать полноценную логистику. Большое количество фирм создает проблему для проведения со стороны государственных органов соответствующей правовой и надзирательной деятельности. Со стороны Федеральной налоговой службы не происходит полного охвата и учета всех участников рынка. Фирмы или частные предприниматели без образования юридического лица включаются в интернет-торговлю, но, к сожалению, часть из них начинает проявлять оппортунистическое поведение. Определенная неразвитость институциональной среды отечественной электронной коммерции позволяет функционировать интернет-торговцам не оформив регистрацию бизнеса, не получив необходимые лицензии или сертификаты, не говоря уже о необходимости уплачивать налоги.

Наличие на рынке интернет-торговли недобросовестных продавцов, создает ситуацию информационной асимметрии, подобной рынку «лимонов» Дж. Акерлофа. Лауреат Нобелевской премии Джордж Акерлоф совместно с Майклом Спенсером и Джозефом Стиглицем в 2001 году были отмечены Нобелевской премией по экономике «за анализ рынков с асимметрично доступной информацией». В своей легендарной статье 1970 г. «Рынок «лимонов»: неопределенность качества и рыночный механизм» [6]. Дж. Акерлоф вывел общие закономерности функционирования рынков со слабой институциональной средой, которая проявляется в неразвитости институтов, создающих необходимую информацию и общие правила и нормы. Хотя Дж. Акерлоф рассматривал конкретный рынок подержанных автомобилей, его выводы носят общий характер и применимы для разных рынков. Дж. Акерлоф писал: «Неформальные, документально не зафиксированные гарантии качества являются непременным условием существования торговли и производства. Если эти гарантии четко не определены, страдает бизнес - так свидетельствует обобщенный нами закон Грешама. Этот аспект неопределенности исследовался специалистами по теории игр, в частности, в связи с так называемой «дилеммой заключенного», но в рамках более традиционного подхода к изучению неопределенности - подхода типа ЭрроуДебре - ему обычно внимания не уделялось. Однако трудность определения качества внутренне присуща миру бизнеса; этот факт позволяет объяснить природу многих экономических институтов и, возможно, является одним из наиболее важных аспектов неопределенности» [1].

Недобросовестные продавцы препятствуют развитию рынка отечественной электронной коммерции, поскольку, с одной стороны, у легальных продавцов выше издержки. Они уплачивают налоги государству, выкупают лицензии, отслеживают качество производимой и продаваемой продукции, подписывают контракты с надежными партнерами. С другой стороны, недобросовестные интернет-магазины подрывают доверие у покупателей ко всей электронной коммерции в целом, особенно у покупателей пожилого возраста.

Важным фактором, определяющим специфику интернет-торговли, является организационно-правовые структуры в виде интернетмагазинов, маркетплейсов, MLM-площадок.

Условием развития цифровой экономики является постоянная генерация научных технологий и внедрение их в производство [5.] Эту функцию в рыночной экономике может и должен взять на себя предпринимательский класс. Роль государства заключается в создании институциональной среды, способствующей динамичному инновационному развитию.

В российской экономике трансформация форм собственности под воздействием современных цифровых технологий сформировала симбиоз крупного, среднего и малого бизнеса при поддержке государства.

\section{Библиографический список}

1. Акерлоф Дж. «Рынок «лимонов»: неопределенность качества и рыночный механизм // THESIS, 1994, вып. 5. C.103.

2. Вольчик В. В. Институциональные подходы к исследованию собственности: возможен ли синтез? // TERRA ECONOMICUS № 2 Tom 12.2014. С. 30.

3. Кастельс М. Информационная эпоха: экономика, общество и культура.- М.: ГУ ВШЭ, 2000.-С. $196-198$. 
4. Попов Е.В. Экономические институты цифровизации хозяйственной деятельности // Управленец. 2019. Том 10. № 2. С. 4. DOI: 10.29141/2218-5003-2019-10-2-1.

5. Трубецкая О. В. Институциональные изменения и цифровая экономика // Экономические науки. 2019 . № 12 (181) c.74-78. DOI: 10.14451/1.181.74.

6. George A.Akerlof. The Market for «Lemons»: Quality Uncertainty and the Market Mechanism //The Quarterly Journal of Economics, v.84, August 1970, p. 488-500. 